\title{
The Slippery Slope of Concession ${ }^{1}$
}

\author{
Jack Hirshleifer, Michele Boldrin, and David K. Levine ${ }^{2}$
}

First version: January 30, 2000

This version: February 26, 2008

\begin{abstract}
We show that with common knowledge and a common rate of time preference, the potential loser can always avoid wasteful conflict through a time-consistent series of small concessions. We examine how the failure of each of these assumptions may explain why conflicts arise. We also debate which actions may be helpful in such unfortunate circumstances.
\end{abstract}

\footnotetext{
1 We would like to thank NSF Grants SES-03-14713 and SES-01-0114147 for financial support.

2 Hirshleifer: Department of Economics, UCLA; Boldrin and Levine Department of Economics, Washington University in St. Louis. The original draft of this paper together with the substantive results was prepared by all three authors. The current draft was prepared after Jack's death on July 26, 2005, and we took the liberty of highlighting Jack's earlier contributions to this literature.
} 


\section{Introduction}

Given that conflict is costly, why does it occur? When both parties believe they are the probable winner, and the winner captures a positive surplus, conflict is the obvious consequence. Should we, then, observe conflict only when both parties expect to win? Many historical and everyday examples suggest that conflict takes place, more often than not, even when one of the two parties is clearly the expected loser, and the loser himself agrees with this prediction. The occurrence of conflict, in this case, is less easy to understand. It is not surprising that one party may expect to gain from a conflict. But, if both parties agree that one side is likely to win, and one to lose, is there not room for the potential loser to make a concession that would avoid the costs of conflict? In other words: Why, in many circumstances, do we fail to observe the expected loser appeasing the expected winner, thereby avoiding conflict and even worse losses? This is the question we pose here, following along the steps of Hirshleifer [2001] and, of course, of the Coase Theorem: If we can make a deal, why fight?

As a practical, and unfortunately everyday more relevant example, the IsraeliPalestinian fight is the paramount case of a conflict that is impossible to understand and resolve on purely rational grounds. Clearly both parties are losing from the fight but, equally clearly, the Palestinian side has lost much more during the last 59 years than the Israeli side. Further, in the foreseeable future, it seems quite unlikely that the Palestinian side will achieve substantial gains through conflict, let alone "win the war." Still, neither side seems willing to undertake serious negotiations to avoid the cost of war. This appears contrary to the consequentialist notion of rational decision making and, we may conjecture that the source of irrationality lies in the religious beliefs of the two parties. Obviously, this explanation cannot be denied a-priori and, as long as conflict continues, it cannot be disproved; still, this paper tries to understand why Israeli and Palestinians may keep fighting even if both were rational actors.

Our main clue is that the apparently avoidable conflicts become unavoidable when a large indivisibility is at stake and there is no third party at hand that can enforce an allocation. The idea that conflict is due to indivisibilities seems to be well understood in the political science literature concerned with conflict. Notice, though, that true 
indivisibilities imply conflict till total defeat of one of the two parties, and this is not often seen in reality. Hence, the "degree" or "size" of the indivisibility is relevant.

Existing analysis of conflict takes place in a static setting. Here we examine the dynamics of conflict, and specifically focus on the problem of time-consistency. We investigate the extent to which the potential loser may not be willing to make a concession, because the potential winner cannot credibly commit to avoiding a conflict even after the concession has been made. After receiving the concession, the potential winner's position is strengthened, and he can demand even more. Recognizing this, the potential loser might choose not to make the initial concession, believing that it will lead to a slippery slope of further demands and further concessions.

Commenting on the claim that war is just trade by other means, Jack Hirshleifer wrote:

I don't recommend thinking of it this way. It is true that, on the individual level, people's motives might be just as mean and nasty in trade as in warfare. The crucial point is that exchange and war are different on the social level. There are two main types of differences. First, trade (if we can assume that transaction costs are negligible) conserves social totals of desired goods, whereas warfare reduces them. Even in the absence of actual battle damage, warfare involves an opportunity cost - due to diverting resources toward the technology of conflict. Second, trade actually does better than merely conserving social totals, since the redistribution thereof is mutually preferred. Warfare, even if there were not too much in the way of battle damage or even opportunity cost, would still not lead to a mutually desired reshuffling of the social totals.

This reasoning suggests that, when choice is possible, trade should be chosen over conflict. Strikingly, in the baseline case of common beliefs and identical time preferences, if the "size" of indivisibility is sufficiently small, conflict can always be avoided by a series of small concessions, with both parties recognizing that there will be 
additional concessions in the future. We provide a rigorous proof of this theorem. ${ }^{3}$ Since conflict is, as a means to accommodate opposing interests, the exception rather than the rule, this result should not be too dismaying. We believe, moreover, that there are valid historical examples where conflict was avoided through a series of small concessions, with both parties correctly expecting additional future concessions. One such example appears to be the extension of the voting franchise in England during the 17th-20th centuries. This took place in gradual increments, and there appears to be explicit recognition that current concessions would lead also to future concessions. Another is the way in which the Spanish constitutional system has handled the Catalonian and Basque requests for progressively more autonomy between 1978 and today. A sequence of small concessions that both parties knew, and know, will continue in the indefinite future, has avoided overt conflict. ETA's terrorist activity is, in this sense, the proof that the process if working. Because ETA has different beliefs from either the Spanish or the Basque mainstream politicians - it clearly believes that conflict would favor the Basque independence cause - and it understands that derailing the small concession process is crucial to force the parties into open conflict, it continues, with little success, its terrorist activities. Among the many possible others, a third significant example is the peace process in the Northern Ireland, or the slow movement toward autonomy for Scotland.

Taking as the starting point a set of assumptions under which conflict can be avoided, we are led then to ask what changes in the assumptions may account for the inevitability of conflict in other circumstances. We identify two major possibilities:

1) Differing rates of time preference. If the potential winner is much more impatient that the loser, he must receive a large concession immediately to avoid conflict. This runs immediately into the time-consistency problem. A large concession will lead to a demand for another large concession, and while the patient loser may be willing to make a series of small concessions, he will not wish to make a series of large concessions.

\footnotetext{
${ }^{3}$ Shavell and Spier [2002] showed this in the case where transfers do not provide a permanent advantage. Schwarz and Sonin [2008] have also show results along similar lines to ours. Their paper contains anice review of the related literature.
} 
2) Indivisibilities. Indivisibilities may lead to conflict for several reasons. If there is a fixed cost for making a concession, then a series of small concessions will be very costly. Constantly haggling over small transfers may be worse than simply fighting it out once and for all. Alternatively, there may be indivisibilities in the resources that are under dispute. For example, there may be natural boundaries, or ethnic mixing, or other physical or social features that make division of a particular region costly. Kosovo might be seen as such an example: forcing the two disputing parties to live side-by-side appeared to be extremely costly. With these types of indivisibilities, a series of small concessions is unfeasible. Randomization is often thought as the "natural" economic solution to the presence of indivisibilities. It is also possible to take turns using the indivisible disputed resource. However both of these solutions run into a time consistency problem - the party who is advantaged will have little incentive to give up the disputed resource when it is its turn to do so.

\section{The Model}

There are two players $\mathrm{i}=1,2$ who must divide a single resource denoted by $\mathrm{x}$ over a sequence of time periods $t=1,2 \ldots$. It is useful to think of this resource as "land" or "territory." We denote by $x_{t}^{i} \geq 0$ the initial amount of the resource held by player $i$ at time $t$. We assume that initially there is a single unit of the resource, so that $\mathrm{x}_{1}^{1}+\mathrm{x}_{1}^{2}=1$.

Players bargain each period over the division of the resource, with impasse resulting in the outbreak of conflict. Put differently, each player may unilaterally start a conflict. Each period $t$ player $i$ makes a demand, which is a real number $y_{t}^{i} \geq 0$ representing the share of the resource player $i$ proposes he should hold at the end of the period. We write $x_{t}=\left(x_{t}^{1}, x_{t}^{2}\right), y_{t}=\left(y_{t}^{1}, y_{t}^{2}\right)$, and so forth. The final allocation of resources each period is determined by the initial allocation, by the demands of the two players and by the presence or absence of a past conflict as follows. If there has been no past conflict then there are two possibilities

Agreement: if $\mathrm{y}_{\mathrm{t}}^{1}+\mathrm{y}_{\mathrm{t}}^{2} \leq \mathrm{x}_{\mathrm{t}}^{1}+\mathrm{x}_{\mathrm{t}}^{2}$ then $\mathrm{x}_{\mathrm{t}+1}^{\mathrm{i}}=\mathrm{y}_{\mathrm{t}}^{\mathrm{i}}$ and there is no conflict.

Disagreement: if $\mathrm{y}_{\mathrm{t}}^{1}+\mathrm{y}_{\mathrm{t}}^{2}>\mathrm{x}_{\mathrm{t}}^{1}+\mathrm{x}_{\mathrm{t}}^{2}$ then a conflict takes place between period $t$ and $t+1$. 
If conflict takes place, because of disagreement, when the resource allocation is $x_{t}$, then we make the simplifying assumption that the game ends. ${ }^{4}$ What this means is that no further demand is advanced, and the future allocations $x_{t+1}, x_{t+2}, \ldots$ are a function of the random outcome of conflict. Players hold state dependent and potentially divergent beliefs over the probability distribution of the random variable "outcome of conflict."

Specifically, given the state $x_{t}$ when conflict erupts, there is a probability distribution over future allocations $\mu_{x_{t}}^{i}\left[x_{t+1}\right]$, representing player $i$ 's beliefs about the consequences of the conflict, after which allocations are supposed to remain constant. This random outcome is closely related to the contest success function discussed, for example, in Hirshleifer [1988], but includes the opportunity costs and damages of conflict, as well as the resources that are gained.

The individual utility as a function of resources controlled in each period is denoted by $u^{i}\left(x_{t}^{i}\right)$; it is continuous and strictly increasing. Inter-temporal preferences are described by discount factors $\delta^{i}$. For any given sequence of $x_{t}^{i}$ 's the average present value of utility is given by

$$
\left(1-\delta^{i}\right) \sum_{t=1}^{\infty}\left(\delta^{i}\right)^{t-1} u^{i}\left(x_{t}^{i}\right)
$$

Since the game effectively ends when a conflict emerges, it is useful also to compute the expected utility that results from a conflict. Since we are using expected average present value, this is just

$$
\mathrm{V}^{\mathrm{i}}(\mathrm{x}) \equiv \int \mathrm{u}^{\mathrm{i}}\left(\mathrm{z}^{\mathrm{i}}\right) \mu_{\mathrm{x}}^{\mathrm{i}}(\mathrm{dz})
$$

The probability distribution $\mu_{x}^{i}$ is assumed to be such that this is continuous and $V^{i}\left(x^{i}, 1-x^{i}\right)$ is strictly increasing in $x^{i}$. Notice that, in this formulation, different beliefs only affect the value of conflict, while different rates of time impatience only affect the value of agreement.

When the two players have the same discount factors, $\delta^{1}=\delta^{2}$, a useful concept is that of the utility possibility frontier as a function of the status quo $x_{t}^{1}+x_{t}^{2}=1$. Because we use average present value, period utility and present values are measured in the same units, hence the utility possibility frontier is $v^{2}=u^{2}\left(1-\left[u^{1}\right]^{-1}\left(v^{1}\right)\right)$. When the

\footnotetext{
${ }^{4}$ The difficulty in allowing the game to continue after a conflict is resolved lies in the fact that it endogenizes the outcome, adding a second layer of complication to the analysis, and one that is not central to the issues discussed here.
} 
two players have different rates of time preference, this concept is less useful because we must take account of the gains to inter-temporal trade.

Our equilibrium concept is sub-game perfection. We pose three questions about conflict: first, is conflict possible? That is, are there sub-game perfect equilibria that involve conflict? Second, is conflict inevitable? That is, do all sub-game perfect equilibria involve conflict? Third, if conflict not inevitable, what is the nature of the settlement paths that avoid conflict - is conflict avoided by a single large concession, or by a series of small concessions?

If $V^{i}(x)>u^{i}(0)$ for both players, then indeed conflict is always possible. Suppose that each player sets $y_{t}^{i}=1$. Given the strategy of the other player, the choice is always either to concede to the other player, resulting in a utility of $u^{i}(0)$, or to "agree" to a conflict, resulting in a utility of $\mathrm{V}^{i}(\mathrm{x})$. In the case where an agreement is preferred to conflict, this equilibrium captures the possibility that an impasse results nevertheless.

More effective (and realistic) bargaining mechanisms may be less prone to impasse than the simple mechanism explored here. Regardless, we will focus on the question of whether conflict is inevitable. Specifically, we will inquire whether an equilibrium exists in which there is no conflict, and in which no resources are discarded. Such an equilibrium, is easy to characterize: it must consist of a series of demands $y_{t}$, for which, in each period $t=1,2, \ldots, \mathrm{y}_{\mathrm{t}}^{1}+\mathrm{y}_{\mathrm{t}}^{2}=1$ and, for both players $\mathrm{i}=1,2$, the present value of utility received from the agreement is at least that from conflict

$$
\left(1-\delta^{\mathrm{i}}\right) \sum_{\tau=\mathrm{t}}^{\infty}\left(\delta^{\mathrm{i}}\right)^{\tau-\mathrm{t}} \mathrm{u}^{\mathrm{i}}\left(\mathrm{y}_{\tau}^{\mathrm{i}}\right) \geq \mathrm{V}^{\mathrm{i}}\left(\mathrm{y}_{\mathrm{t}-1}\right),
$$

where it is convenient to define $y_{0}=x_{1}$.

\section{Classification of Environments}

Following Hirshleifer [1989], we can characterize the possibilities for conflict according to the relationship between the status quo $u\left(x_{t}\right)=\left[u^{1}\left(x_{t}^{1}\right), u^{2}\left(x_{t}^{2}\right)\right]$ and the expected result of conflict $\left.V\left(x_{t}\right)=N^{1}\left(x_{t}\right), V^{2}\left(x_{t}\right)\right]$. In our model, we can distinguish three cases: 
(1) $u^{i}\left(x_{t}^{i}\right) \geq V^{i}\left(x_{t}\right), i=1,2$. Here both players agree that conflict is undesirable. Conflict is not inevitable; both players setting $y_{t}^{i}=x_{t}^{i}$ is clearly sub-game perfect. We will not discuss this case further.

(2) $u^{i}\left(x_{t}^{i}\right)<V^{i}\left(x_{t}\right), i=1,2$. Here both parties agree that conflict is preferred to the status quo.

(3) $V^{2}\left(x_{t}\right) \geq u^{2}\left(x_{t}^{2}\right), V^{1}\left(x_{t}\right) \leq u^{1}\left(x_{t}^{1}\right)$ or $V^{2}\left(x_{t}\right) \leq u^{2}\left(x_{t}^{2}\right), V^{1}\left(x_{t}\right) \geq u^{1}\left(x_{t}^{1}\right)$, where only one inequality may be weak in either case. In this case one party benefits from a conflict and the other does not. This is the case we will focus most of our attention; without loss of generality we always study the first case, in which player 2 expects to benefit from the conflict.

How does this model of pre-conflict negotiations compare to the standard bargaining framework of Rubinstein [1982] and Stahl [1972]? Rubinstein/Stahl is a model of post-conflict - or, more appropriately, in-conflict - negotiation: losses are incurred until an agreement is finally reached, at which point the game ends. In the model we study, losses occur after a conflict begins, at which time the game ends. While Rubinstein/Stahl model negotiations designed to end an ongoing conflict, we model negotiations designed to prevent a conflict from starting.

The other widely used model of conflict is that of the war of attrition. This is similar to Rubinsten/Stahl in the sense that losses occur until one side gives up. Unlike Rubinsten/Stahl, no intermediate division of resources is possible; conflict can end only with one party conceding everything.

Finally, there is the possibility that the beliefs $\mu_{\mathrm{x}_{\mathrm{t}}}^{\mathrm{i}}$ while different between players are drawn from an underlying common knowledge distribution. This case has been extensively studied in the bargaining literature, for example by Admati and Perry [1987], where it is quite relevant, since failure to reach agreement may be a signal of private information. It is less relevant in this setting, since failure to agree leads to conflict and the end of the game.

Note that Hirshleifer [1989] considers also the more general case in which the status quo may lie below the utility possibility frontier. For example, perhaps one player has fish and the other corn - but they have not learned how to trade. In this setting, conflict may be a substitute for trade, so that a conflict may actually be an improvement 
over autarky. It is not difficult to see that, apart from the fact that the starting point is not on the utility possibility frontier, this case falls either under case (2) or case (3). We study case (2) first.

\section{Conflict Preferred to the Status Quo}

When conflict is preferred to the status quo by both parties, we might expect conflict to be inevitable. Notice first that such a situation may arise because the status quo is not Pareto efficient; then moving to a Pareto efficient point may dominate conflict for at least one of the two parties, which means that conflict is not inevitable as shown in the next section.

A particular reason for which the status quo may fail to be Pareto efficient is that the two players have different rates of time preference. In this case, simply choosing $x_{1}$ every period will be Pareto dominated by sequences of allocations that transfer some resources to the less patient player in early periods and more resources to the more patient player in later periods. It is also true, though, that different rates of time preferences may also be the reason for which even a Pareto efficient status quo is dominated by conflict in a more general context. For example, assume the status quo does not consist of a constant sequence but, instead, of a time-dependent one that provides the impatient agent with high payments in the far future. Symmetrically, assume that conflict transfers at least part of these payments to nearer dates, and vice versa for the patient agent. Then, conflict is preferred to status quo by both agents. Notice, though, that also in this case, conflict is not inevitable: in general, there may exist a feasible inter-temporal rearrangement of the payoff sequences that is preferred, at least by one of the two parties, to conflict. Because addressing this case requires considerations of inter-temporal trade and, therefore, the introduction of at least a simplified form of inter-temporal production/accumulation, we leave it for future research and focus on the "static" constant-allocations case described above. Hence, for the remainder, we limit attention to equally patient parties, that is, $\delta^{1}=\delta^{2}=\delta$.

For the reason explained earlier, we also focus on situations where the status quo is Pareto efficient. If the status quo is Pareto efficient and it is still true that both parties prefer conflict to the status quo, then it is clear that every socially feasible sequence $y_{t}$ is 
strictly worse for one player than the result of conflict, so that player will always prefer an action resulting in conflict.

To move forward with intuition, consider the two extreme cases in which the

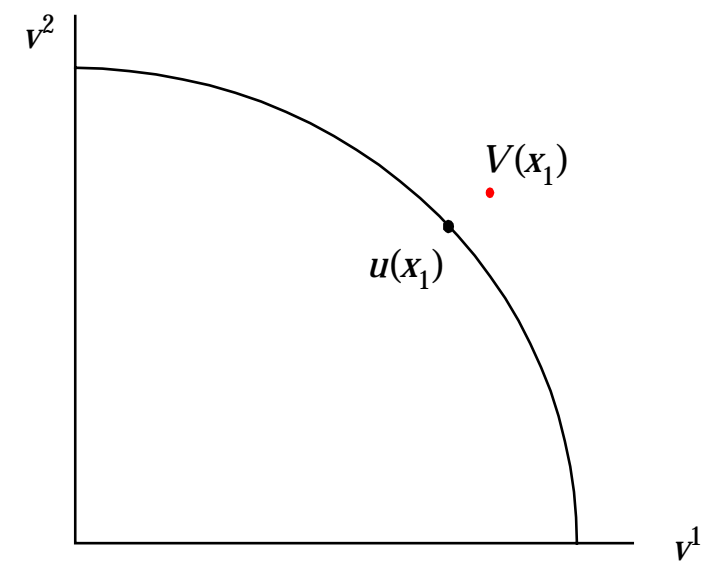

utility possibility frontier is globally either concave or convex.

\subsection{Concave Utility Possibilities}

Suppose that the utility possibility frontier is concave. ${ }^{5}$ The situation is that pictured below. Because the discount factors are equal, the status quo $u\left(x_{1}\right)=\left[u\left(x_{1}^{1}\right), u\left(x_{1}^{2}\right)\right]$ is Pareto efficient. Notice however, that the expected result of conflict $\mathrm{V}\left(\mathrm{x}_{1}\right)$ is not socially feasible. This can occur only because the two players have different beliefs about the result of the conflict, that is, $\mu^{1} \neq \mu^{2}$. In effect, both players think they will win, even though both cannot be right. For example, players may both have an optimistic bias as in the bargaining models of Ali [2006] or Yildiz [2003]. This failure of common knowledge can clearly lead to conflict. Since sufficiently divergent beliefs can always make conflict inevitable, for the remainder of the paper, we will restrict further to the case in which $\mu^{1}=\mu^{2}$, that is, the case of common knowledge.

\footnotetext{
${ }^{5}$ Note that unlike Hirshleifer [1989] the diagrams here are in the space of utilities, not the space of resources.
} 
Jointly, the assumptions of common knowledge, common discount factor, concave utility possibilities and Pareto efficient status quo have the implication not only that the expected result of conflict must be socially feasible, but that it is socially wasteful. Indeed, unless the distribution $\mu$ is degenerate, the outcome of conflict must in fact be inefficient, that is, interior to the utility possibility frontier.

\subsection{Convex Utility Possibilities}

We can describe this as "this town ain't big enough for both of us." What convexity does is to make conflict more "likely" in the space of utility allocations, as the more convex the frontier is, the "fewer" are the set of allocations that are interior to it. Notice in this case that both a lottery and a deterministic alternation could be Pareto improving. Regardless, neither is an equilibrium. Consider a situation such as that illustrated below. Let $x_{A}, x_{B}$ be the division of resources corresponding to the points A and $\mathrm{B}$, respectively; that is, $u\left(x_{A}\right)=A, u\left(x_{B}\right)=B$, where also $A$ and $B$ are to be read as two-dimensional vectors. Here, a one time lottery between $x_{A}$ forever and $x_{B}$ forever is preferred to both the status quo and to conflict. If the discount factor $\delta$ is sufficiently close to one, then there is also a deterministic alternation between $x_{A}$ and $x_{B}$ which is

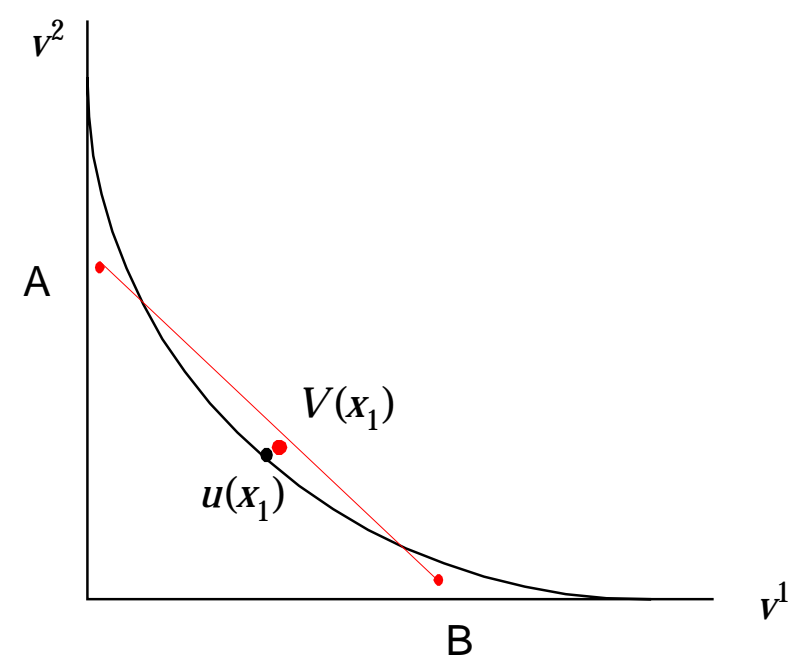

preferred to both the status quo and to conflict.

Let us examine a once-and-for-all lottery first. Suppose, for example, that the outcome of the lottery is $x_{A}$. Then player 1 will refuse to honor the agreement, since he 
prefers the conflict $V^{1}\left(x_{1}\right)>A^{1}$. Without a third party to enforce the agreement, onceand-for-all lotteries are impossible.

Turning to deterministic alternation, let us suppose that the condition $V(x) \geq u(x)$ holds globally, not merely at $x_{1}$; notice that this is tantamout to assuming that the possibility frontier is strongly convex. Assume that $x_{A}$ is supposed to occur first, followed by $x_{B}$, and then repeating. Let $U_{A}=A+\delta B, U_{B}=B+\delta A$ be the average present value of the alternation beginning from $\mathrm{A}$ and $\mathrm{B}$ respectively; again $U_{A}=\left[U_{A}^{1}, U_{A}^{2}\right]$, and so on. Then, in the second period, player 2's must give up $V^{2}\left(x_{A}\right)$ in exchange for $U_{B}^{2}$. But we have assumed that $V^{2}\left(x_{A}\right) \geq A^{2}$ and $A^{2}>U_{B}^{2}$. This means that player 2 will not agree to the second stage of the alternation, and so conflict is inevitable.

An attempt at this type of alternation took place after the death of President Tito in 1980, with the alternating Presidency, in Yugoslavia. The system worked reasonably well until 1989. During the first eight years the six member states and two provinces were ruled by politicians belonging to the same party, the League of Communists of Yugoslavia (LCY). Nobody was proposing separation, and decisions were taken "collegially" by the eight presidents together with the secretary of the LCY; this group of nine people constituted, in fact, the office of the Presidency. When the communist regime collapsed, between 1988 and 1989, the constitution was reformed, excluding the communist party secretary from the office of the Presidency. During the same year, independence-minded non-communist presidents were elected in both Slovenia and Croatia and this, for the first time, made conflict possible. The alternating Presidency system was nevertheless maintained, and Slovenia went first, with Janez Drnovsek, during 1989; 1990 was Serbia's turn, to be followed by Croatia. Of course, when it was Serbia's turn to surrender the Presidency to Croatia, no Croatian candidate was good enough, and the rotating Presidency ended in conflict. 
This example suggests an answer to the question: why should the utility possibility frontier be convex? An obvious possibility is that there is an indivisibility: consider for example the concave utility possibility frontier below. If we assume that the resource is completely indivisible, so that only one of the two parties can hold it, we get instead the red convex utility possibility frontier.

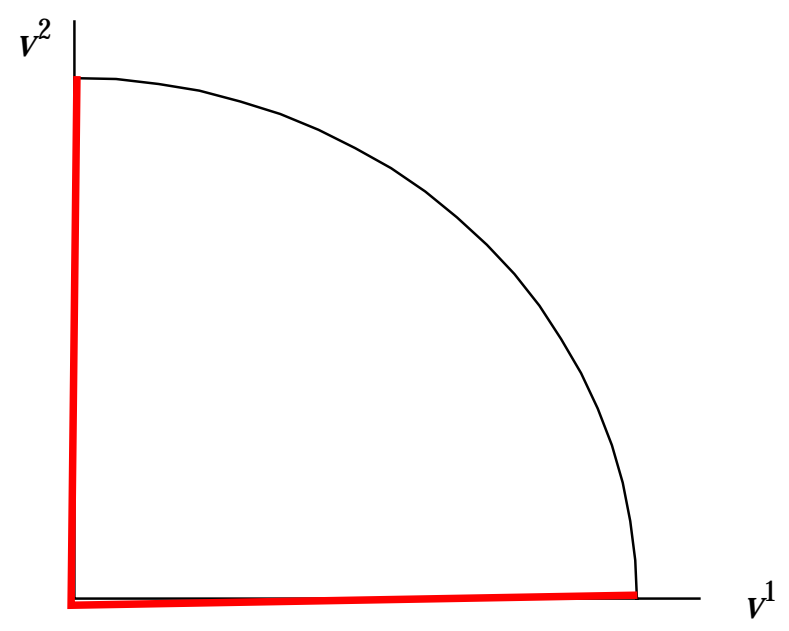

Examples of indivisibilities can involve choices between different ethnic groups or opposing political or religious systems. If there are economies of scale in operating these systems, having two systems trying to share an area may result in a great loss compared to a single system.

\section{One Side is the Winner, Conflict is Costly}

Without loss of generality assume that $V^{2}\left(x_{1}\right)>u^{2}\left(x_{1}^{2}\right), V^{1}\left(x_{1}\right)<u^{1}\left(x_{1}^{1}\right)$. By costly conflict, we mean that the vector $\mathrm{V}(\mathrm{x})$ corresponding to conflict lies strictly inside the Pareto frontier for all $\mathrm{X}$. As we have observed, if both sides think they are going to win, or if there are large indivisibilities, this will not be the case. However, if the utility possibility frontier is strictly concave, beliefs are common, and the outcome of conflict is uncertain, this will always be the case.

\subsection{Equal Patience}

Proposition: If beliefs are common $\mu^{1}=\mu^{2}$, conflict is socially costly and $\delta^{1}=\delta^{2}$ then conflict is not inevitable 


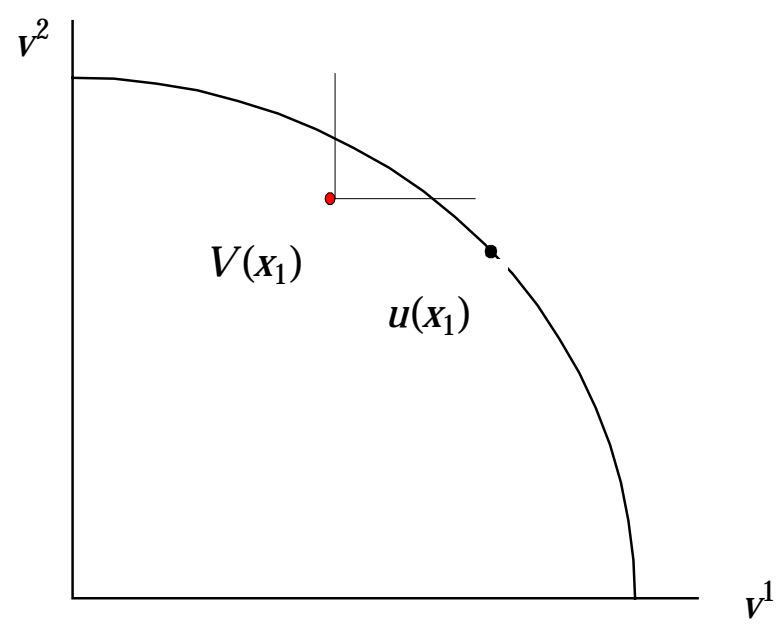

Proof: Let $\mathrm{x}_{1}$ denote the status quo and consider the situation described in the figure above. First note that if we consider points $y$ on the Pareto frontier with $y^{1} \leq x_{1}^{1}$, as we reduce $y^{1}$ and $u(y)$ moves up and left we eventually reach a point where $u(y) \geq V(y)$. Denote this point by $\mathrm{y}_{\infty}$. We give a formal argument below. Once we reach this point, there is no longer any reason for conflict, and the concession schedule becomes $y_{t}=y_{\infty}$. In the range where player 1 's share $y^{1} \in\left[y_{\infty}^{1}, x_{1}^{1}\right]$ we have $u^{2}\left(1-y^{1}\right) \leq V^{2}(y)$ : that is, player 2 is tempted by conflict. The second step of the proof is to work recursively backwards from $\mathrm{y}_{\infty}$ showing how to construct a concession schedule that satisfies the desired inequality

$$
(1-\delta) \sum_{\tau=\mathrm{t}}^{\infty} \delta^{\tau-\mathrm{t}} \mathrm{u}^{\mathrm{i}}\left(\mathrm{y}_{\tau}^{\mathrm{i}}\right)>\mathrm{V}^{\mathrm{i}}\left(\mathrm{y}_{\mathrm{t}-1}\right) \mathrm{i}=1,2
$$

\section{Step 1:}

If $\mathrm{u}(\mathrm{y})<\mathrm{V}(\mathrm{y})$ for all efficient $\mathrm{y}$ with $\mathrm{y}^{1} \leq \mathrm{x}_{1}^{1}$, then $\mathrm{u}^{2}(1)<\mathrm{V}^{2}(0,1)$ implying that $V(0,1)$ is infeasible. Because conflict is costly, it contradicts $\mu^{1}=\mu^{2}$. This establishes the existence of $\mathrm{y}_{\infty}$.

\section{Step 2:}

Suppose that, for $\mathrm{y}^{1} \in\left[\mathrm{y}_{\infty}^{1}, \mathrm{x}_{1}^{1}\right], \mathrm{u}^{2}\left(1-\mathrm{y}^{1}\right) \leq \mathrm{V}^{2}(\mathrm{y})$. Suppose, further, that we are given an efficient continuation sequence starting at time $t$; we will show that we can extend 
this backwards for a period. That is, we are given efficient sequence $\left(y_{t}, y_{t+1}, \ldots\right)$ with $\mathrm{y}_{\tau}^{1} \in\left[\mathrm{y}_{\infty}^{1}, \mathrm{x}_{1}^{1}\right]$ and some efficient $\hat{\mathrm{y}}_{\mathrm{t}-1}$ with $\hat{\mathrm{y}}_{\mathrm{t}-1}^{1} \geq \mathrm{y}_{\mathrm{t}}^{1}, \hat{\mathrm{y}}_{\mathrm{t}-1}^{2} \in\left[\mathrm{y}_{\infty}^{2}, \mathrm{x}_{1}^{2}\right]$ and

$$
(1-\delta) \sum_{\tau=\mathrm{t}}^{\infty} \delta^{\tau-\mathrm{t}} \mathrm{u}^{\mathrm{i}}\left(\mathrm{y}_{\tau}^{\mathrm{i}}\right)>\mathrm{V}^{\mathrm{i}}\left(\hat{\mathrm{y}}_{\mathrm{t}-1}\right) \mathrm{i}=1,2
$$

Our goal is to find the appropriate value of $y_{t-1}$. As we move to the right along the Pareto frontier, thereby increasing $\mathrm{y}_{\mathrm{t}-1}^{1}$, by assumption $\mathrm{V}^{1}\left(\mathrm{y}_{\mathrm{t}-1}\right)$ increases and $\mathrm{V}^{2}\left(\mathrm{y}_{\mathrm{t}-1}\right)$ decreases, and since $V$ is continuous, either $y_{t-1}^{2}=x_{1}^{2}$, in which case we stop, or the inequality for player 1 must hold with exact equality at some point $\hat{y}_{t-2}$; at that point strict inequality $\mathrm{u}^{2}\left(\mathrm{y}_{\mathrm{t}-1}^{2}\right)>\mathrm{V}^{2}\left(\hat{\mathrm{y}}_{\mathrm{t}-2}\right)$ must still hold for $\mathrm{i}=2$. If we continue to increase $\mathrm{y}_{\mathrm{t}-1}^{1}, \mathrm{u}^{2}\left(\mathrm{y}_{\mathrm{t}-1}^{2}\right)$ falls, and since eventually it falls below $\mathrm{V}^{2}\left(\hat{\mathrm{y}}_{\mathrm{t}-2}\right)$, there is a unique point $\mathrm{y}_{\mathrm{t}-1}$ on the Pareto frontier where $\mathrm{u}^{2}\left(\mathrm{y}_{\mathrm{t}-1}^{2}\right)=\mathrm{V}^{2}\left(\hat{\mathrm{y}}_{\mathrm{t}-2}\right)$. Since $\mathrm{V}^{2}\left(\hat{\mathrm{y}}_{\mathrm{t}-2}\right)<\mathrm{V}^{2}\left(\hat{\mathrm{y}}_{\mathrm{t}-1}\right)$, it follows from $(*)$ that

$$
(1-\delta) \sum_{\tau=\mathrm{t}}^{\infty} \delta^{\tau-\mathrm{t}} \mathrm{u}^{2}\left(\mathrm{y}_{\tau}^{2}\right)>\mathrm{v}^{2}\left(\hat{\mathrm{y}}_{\mathrm{t}-2}\right)=\mathrm{u}^{2}\left(\mathrm{y}_{\mathrm{t}-1}^{2}\right)
$$

This in turn implies that

$$
(1-\delta) \sum_{\tau=\mathrm{t}-1}^{\infty} \delta^{\tau-\mathrm{t}} \mathrm{u}^{2}\left(\mathrm{y}_{\tau}^{2}\right)>\mathrm{V}^{2}\left(\hat{\mathrm{y}}_{\mathrm{t}-2}\right)
$$

which is half of the desired conclusion - for player 2 .

Since we did not stop at $\mathrm{y}_{\mathrm{t}-1}^{2}=\mathrm{x}_{1}^{2}$, but before that point, $\mathrm{u}^{2}\left(1-\hat{\mathrm{y}}_{\mathrm{t}-2}^{1}\right) \leq \mathrm{V}^{2}\left(\hat{\mathrm{y}}_{\mathrm{t}-2}\right)$, which also implies from the monotonicity of $\mathrm{u}^{2}$ that $\hat{\mathrm{y}}_{\mathrm{t}-2}^{1} \geq \mathrm{y}_{\mathrm{t}-1}^{1}$. For player 1 , since $\mathrm{u}^{2}\left(\mathrm{y}_{\mathrm{t}-1}^{2}\right)=\mathrm{V}^{2}\left(\hat{\mathrm{y}}_{\mathrm{t}-2}\right)$, and since $\mu^{1}=\mu^{2}$ and conflict is costly imply that $\mathrm{V}$ is interior to the utility possibility frontier, it follows that $u^{1}\left(y_{t-1}^{1}\right)>V^{1}\left(\hat{y}_{t-2}\right)$. Since $u, V$ are continuous and so uniformly continuous on the compact square $\left[\mathrm{y}^{1}, \mathrm{x}^{1}\right]$, it also follows that $\mathrm{y}_{\mathrm{t}-1}^{1} \geq \hat{\mathrm{y}}_{\mathrm{t}-2}^{1}+\varepsilon \geq \mathrm{y}_{\mathrm{t}}^{1}+\varepsilon$ for a uniform bound $\varepsilon>0$. Since by construction

$$
(1-\delta) \sum_{\tau=\mathrm{t}}^{\infty} \delta^{\tau-\mathrm{t}} \mathrm{u}^{1}\left(\mathrm{y}_{\tau}^{1}\right)=\mathrm{V}^{1}\left(\hat{\mathrm{y}}_{\mathrm{t}-2}\right)
$$

we have

$$
(1-\delta) \sum_{\tau=\mathrm{t}-1}^{\infty} \delta^{\tau-\mathrm{t}} \mathrm{u}^{1}\left(\mathrm{y}_{\tau}^{1}\right)>\mathrm{V}^{1}\left(\hat{\mathrm{y}}_{\mathrm{t}-2}\right)
$$

This is the second half of the desired conclusion - for player 1 .

Since the construction shows that $\mathrm{y}_{\mathrm{t}-1}^{1} \geq \mathrm{y}_{\mathrm{t}}^{1}+\varepsilon$, it follows that this construction must eventually stop at $\mathrm{y}_{\mathrm{t}-1}^{2}=\mathrm{x}_{1}^{2}$. 
There is a crucial point to emphasize: while conflict can be avoided, the solution is not Pareto efficient if the utility possibility frontier is strictly concave. This is because the present value of utility is the average of different points on the frontier, and so lies interior to the frontier. Indeed, it is this fact that complicates the proof - if we could simply find a single stationary point that was time-consistent and Pareto dominated conflict, then that would be the obvious solution. But here a series of concessions must take place over time, and while the cost of conflict is avoided, the solution is still inefficient relative to what could be achieved, for example, if there was a third party that could enforce a contract.

\subsection{Concession Indivisibilities}

If there are indivisibilities in the size of concessions, then conflict may be inevitable. In order to find a concession that will be agreed to by both sides, it must be large enough to please the winner, but small enough to satisfy the loser. The problem is that if the minimum size of the concession is quite large, it may be impossible to satisfy the loser. This was illustrated graphically in the concession by Czechoslovakia of the Sudetenland that led to Chamberlain's infamous "peace in our time" speech. The problem was that the Sudetenland is a mountainous area on the border - essential to the defense of Czechoslovakia and not easily divisible. To be successful the concession needed to be small enough to avoid conflict in the subsequent period. In this case, the concession was so large, that the next demand by Nazi Germany was for all of Czechoslovakia. In the presence of large indivisibilities, appeasement might not work. But the usual conclusion that appeasement is always a bad idea, does not follow. As we have shown when suitably small concessions are possible, it may work quite well.

\section{Conclusion}

In a sense the basic topic of this paper is appeasement: when does it work? If the parties agree that peace is preferable to conflict, and if there are not important indivisibilities either in the allocation of resources (the utility possibility frontier is concave) or in the making of concessions (small concessions are possible), then conflict is avoidable. This is not to say that appeasement is inevitable - there are equilibria in 
which negotiations fail and conflict takes place, but under these circumstances negotiations have the possibility of leading to a lasting peace. To a large extent the world breaks itself into two camps regarding conflict. There are those who believe that any concession is the beginning of a slide down a slippery slope and that appeasement is a dirty word. And there are those that believe that all of the worlds problems could be solved if only the parties could be brought to the bargaining table. The model here suggests that both groups may be both right and wrong. When small concessions are possible, an equitable division of resources is good (the utility possibility frontier is concave) and there is equal patience, a series of small negotiated concessions may indeed avoid conflict. When these conditions fail, appeasement may be dangerous indeed.

\section{References}

Admati, Anat, and Motty Perry [1987], "Strategic delay in bargaining," Review of Economic Studies 54: 345-364.

Ali, S. Nageeb [2006], "Multilateral Bargaining with Subjective Biases: Waiting To Settle," Journal of Economic Theory 127: 109-137.

Hirshleifer, Jack [1988], “The analytics of continuing conflict,” Synthese 76:201-33.

Hirshleifer, Jack [1989], "Conflict and rent-seeking success functions: Ratio vs. difference models of relative success," Public Choice 63:101-12.

Hirshleifer, Jack [1991], "The paradox of power," Economics and Politics 3:177-200. 
Hirshleifer, Jack [1991], “The Technology of Conflict as an Economic Activity," The American Economic Review 81: 130-134.

Hirshleifer, Jack [2001], “Appeasement: Can It Work?” The American Economic Review 91:2 (May) 342-346.

Rubinstein, Ariel [1982], "Perfect Equilibrium in a Bargaining Model," Econometrica 50: $97-110$.

Schwarz, M. and K. Sonin [2008], "A Theory of Brinkmanship, Conflicts and Commitment," Journal of Law, Economics and Organization, forthcoming.

Shavell, S. and K. Spier [2002], "Threats Without Binding Commitments," B.E. Journal of Economic Analysis and Policy.

Stahl, I. [1972] Bargaining Theory, Stockhold: Stockholm School of Economics.

Szayna, Thomas S. [2000], Identifying Potential Ethnic Conflict: Application of a Process Model, Santa Monica, RAND Corporation

Yildiz, Muhamet [2003], "Bargaining without a common prior - An immediate agreement theorem," Econometrica 71: 793-811

Young, H. Peyton [1995] "Dividing the Indivisible" American Behavioral Scientist 38(6): 904-20. 